\title{
Memoria, ideología y heterodoxia: Contra el pensamiento hegemónico
}

JOSÉ COLMEIRO

Los dos primeros versos de la "Oda al partido" [son]: "Tienes dos ojos/ pero el Partido tiene mil". No hay duda de que Brecht lo escribió primando la mirada colectiva sobre la mirada individual. Con el paso de los años, he pensado que se podría invertir la fórmula: Aunque el Partido tenga mil ojos /siempre debes conservar los dos tuyos". Si no, se cae en la militancia religiosa, que es la que ha destrozado el socialismo real.

MVM, Geometrías de la memoria (Georges Tyras 31)

Vázquez Montalbán se ha definido en diferentes momentos de su vida pública, más o menos seriamente, como espartaquista, luxemburguista, grouchomarxista, eurocomunista, anarquista y postmarxista. La proliferación de términos define tanto su constante militancia en la izquierda como una permanente actitud crítica de ella que gusta situarse en sus márgenes. Tanto la dificultad de definir su propia posición en tiempos de rapidísima erosión en la significación de la identidad de la izquierda, como la conciencia de que el eje de esta izquierda sigue siendo, en gran medida, el marxismo.

Mari Paz Balibrea, En la tierra baldía (10)

En una época marcada por las incertidumbres y rebajas ideológicas posteriores a la caída del muro de Berlín, Vázquez Montalbán resumía con habitual claridad y precisión su fundamental compromiso ético, al ser preguntado por su colega Eduardo Haro Tecglen sobre su continua militancia política: "Y tú, ¿por qué sigues siendo comunista?'. Y me contestaste: 'Por el militante de base'. ("Conversación"). Ante la ruina del comunismo como ideología del estado tras la caída del Muro de Berlín y la desaparición de la Unión Soviética, y plenamente consciente del consiguiente desprestigio o abandono por parte de los sectores de la izquierda, ante el triunfo del neoliberalismo como ideología universal de la globalización y la dictadura de los mercados, Vázquez Montalbán se mantenía fiel a sus principios, y a su profundo compromiso ético y sentimental con su vida, su memoria y su gente. Esta postura de fidelidad consigo mismo y con sus ideales ya había quedado claramente reflejada en otra ocasión anterior, hacia finales de los años ochenta, en la que su amigo Josep Ra- 
moneda le preguntó sobre su "obstinada fidelidad al comunismo", cuando todos parecían ya haber empezado a abandonar la nave en medio del naufragio ideológico del fin de milenio. Como respuesta, Vázquez Montalbán contestó sumariamente diciendo: 'Déjame que sea el que apague la luz'.

Se puede decir que la relación de Vázquez Montalbán con el comunismo a lo largo de casi 50 años fue tan compleja como coherente, tanto en su vida como en su prolífica obra periodística, ensayística y literaria. Por un lado, se trata de una relación de gran fidelidad a sus propios principios ideológicos de emancipación de los sectores populares más marginados, y también en gran parte como fidelidad a su propia memoria, a su identidad familiar y social, y a la historia. Por otro lado, Vázquez Montalbán siempre mantuvo una postura crítica de confrontación frente al aparato político comunista y a sus dogmatismos, desavenencias y desencantos (del estalinismo y el socialismo real a la desvirtualización del eurocomunismo en la transición y la pérdida de referentes de la izquierda posteriormente). Esta aparente tensión siempre ha estado presente a lo largo de su actividad política e intelectual. Su característica postura crítica frente a cualquier dogmatismo u obcecación ideológica se fundamentaba en unos sólidos principios éticos e ideológicos que supieron adecuarse y servir de instrumento crítico de acercamiento a la realidad política y social de cada momento, y así optar por determinadas respuestas políticas, según las diferentes coyunturas políticas y sociales del momento histórico vivido.

Es cierto que la sensación de desencanto ha tendido a dominar la particular visión del mundo y la sociedad por parte de Vázquez Montalbán, quizás porque la realidad suele acabar traicionando los mejores deseos, individuales y colectivos, y las grandes ilusiones de lograr un mundo mejor, más justo y más equitativo, no solo no se han cumplido sino que ellas mismas han perecido en el naufragio de los grandes ideales a lo largo del siglo que le tocó vivir al autor catalán. Es por esa razón que permanece un sentimiento apesadumbrado de melancolía y derrota colectiva de los grandes ideales de emancipación que han movido a la izquierda, desde la constatación de que la vida "no es como la esperábamos", en palabras de Gil de Biedma (119), y de que "la historia no es como nos la merecíamos", frase recurrente en la obra de Vázquez Montalbán. Pero a pesar de ello, su postura está muy lejos de llegar a la clau- 
dicación, la resignación o la mutación ideológica, caso de tantos otros intelectuales españoles comunistas y antifranquistas de otro tiempo, que acabaron pasándose a servidores del poder (la lista sería enorme, pero todo el mundo puede pensar en muchas figuras conocidas que ilustran esta tendencia). ${ }^{1}$ Muy al contrario, Vázquez Montalbán siempre se mantuvo en una posición de vanguardia política, de continua reivindicación de los valores revolucionarios, de las reivindicaciones de los movimientos obreros y de los sectores emergentes y marginales, en búsqueda de respuestas a los nuevos retos políticos y sociales del momento, tratando de encontrar nuevas vías alternativas en las que encauzar su pensamiento político. ${ }^{2}$ Por ello, a lo largo de su trayectoria se dedicó a apoyar y colaborar con toda una serie de nuevas iniciativas políticas de izquierda originadas en España, y más concretamente en Cataluña, en el posfranquismo, del PSUC a Izquierda Unida a Iniciativa per Catalunya/Els Verts, y sus inquietudes le llevaron a buscar otras alternativas fuera del entorno español, particularmente en Latinoamérica en la última etapa de su vida. ${ }^{3}$

La coherencia intelectual de Vázquez Montalbán estaría anclada en una ética del compromiso, una continua lucha por encontrar respuestas a las demandas que siempre han movilizado a la izquierda: la lucha por la emancipación, la liberación, la justicia económica y social. Esta postura ética y política se mantuvo firme a lo largo de toda su trayectoria, si bien desde una posición de constante autocrítica y distanciamiento de los planteamientos ortodoxos tradicionales y una defensa de los avances históricos. Así su trayectoria se podría resumir en tres periodos clave: 1)

$-$

1 Véase al respecto mi estudio introductorio de su novela El pianista (1985), en cuya primera parte se presenta con gran ironía crítica la gran transformación ética de toda una generación y la decadencia de los valores de la izquierda una vez instalados en el poder. 2 Véase el estudio pionero de Mari Paz Balibrea (1999) citado como epígrafe en este artículo, que ubica la trayectoria de Vázquez Montalbán y su obra dentro de las corrientes de izquierda de su tiempo. Véanse asimismo los trabajos de José María Izquierdo (2001, 2013), que analizan el compromiso social, ético y estético en la obra del autor y sus estrategias narrativas.

3 Aunque sus reflexiones políticas son muy abundantes tanto en su obra ensayística como la literaria y periodística, quizás su programa político más comprensivo se muestre en el libro Rafael Ribó: el optimismo de la razón (1988), donde se analiza el proyecto de una alternativa de izquierdas "poscomunista", Iniciativa per Catalunya, en la que él mismo participó muy activamente como uno de sus fundadores. 
Implicación en el movimiento comunista de la posguerra como vanguardia de la resistencia frente a la dictadura franquista; 2) crítica al comunismo posibilista de la Transición, con sus pactos con el poder, y la decadencia de los modelos tradicionales de izquierda; y 3) búsqueda de nuevos modelos de resistencia a la globalización neoliberal y nuevos sujetos históricos de cambio (en los movimientos de antiglobalización, el zapatismo o el indigenismo).

El propio Montalbán señalaba, no sin su característica nota de ironía, la continuidad ideológica de su trayectoria que se podría resumir en una ética de compromiso, con una realidad social y una memoria histórica, y una lucha emancipatoria, más allá de los avatares políticos o de las puntuales desavenencias con las estrategias de partido:

"El compromiso con las ideas es el compromiso con la realidad y en saber qué es la realidad política, social, histórica desde siempre. Esto se asume cuando uno nace en un mundo de víctimas, de una guerra civil. Es un compromiso que no le abandona a uno en la vida y que le lleva a buscar instrumentos para cambiar las cosas. El compromiso político es como un matrimonio que se hace con infinidad de personas que comulgan con tus mismas ideas. En muchos momentos, el funcionamiento o las actitudes del partido pueden chocar con tus posiciones o credo personal. Algunas veces te equivocas tú y otras se equivoca la institución, pero siempre ha funcionado en mí el que no se produjera la ruptura porque confiaba fundamentalmente en el instrumento" ("Encarna soy yo", La Calle, 23-10-1979).

Josep Ramoneda resumió con concisión la trayectoria ideológica de Vázquez Montalbán, en una lucha ideológica incansable contra el poder hegemónico y una constante coherencia y voluntad de mantenerse fiel a sus principios:

Vázquez Montalbán siguió fiel al comunismo y sus sucesivas metamorfosis, siguió escribiendo desde el compromiso con las propuestas emancipatorias, para decirlo con su lenguaje, y buscando potenciales nuevos agentes del cambio, fiel a la idea de que el mundo es una pugna entre el poder económico que bloquea cualquier proceso que no controle y los sectores sociales sometidos que luchan por su emancipación.

Vázquez Montalbán siempre mantuvo una marcada conciencia de clase, debido a sus humildes orígenes proletarios, y de la tradi- 
ción de pensamiento de izquierda, por razones tanto ideológicas como sentimentales, de compromiso con su memoria vivida y con sus gentes, algo que no le abandonará en toda su vida, a pesar de sus grandes éxitos profesionales. Como escritor de gran éxito popular y marcada ideología comunista, esta aparente contradicción fue advertida por muchos de sus críticos, normalmente en posiciones ideológicas adversas. Esta fidelidad a sus convicciones ideológicas, a su trayectoria personal y a su grupo social, responde a su doble creencia en la función social del intelectual en la sociedad moderna de masas, ante todo como una responsabilidad ética, y en la necesidad de mantener un posicionamiento crítico frente al sistema hegemónico. Como ha señalado Francesc Salgado en relación a la actividad periodística de Vázquez Montalbán, pero una observación que puede ser ampliada a la totalidad de su obra: "En realidad se sintió siempre obligado a defender su punto de vista, su opinión, que para él era la de su clase. Nunca quiso dejar de influir. El periodismo de Vázquez Montalbán muestra una especial intensidad porque se sabe en medio de una pugna ideológica de gran importancia estratégica" (21).

En su biografía revisada del autor, José Saval relata que Vázquez Montalbán resultó "muchas veces marginado y excluido por sus ideas comunistas, nunca comulgó con la ortodoxia marxistaleninista y mostró un furibundo antiestalinismo como ante cualquier forma opresiva de poder" (111). Un "marxista inclasificable" según Rafael Ribó, y en general siempre fue un "marxista incómodo para los aparatos del partido (...) un heterodoxo que creyó toda su vida en un socialismo emancipador, no secuestrado por el estalinismo" (111). En opinión de Díaz Alonso: "Poco dado al maximalismo, los dogmas y a la mitomanía, excesivamente irónico para unos, librepensador, equidistante entre nacionalismo español y nacionalismos periféricos, Montalbán fue dentro del PCE-PSUC un comunista muy particular, alejado de cualquier sectarismo o visión estrecha del tipo "tribu contra tribu" (4). Podía valorar los avances emancipatorios de la revolución soviética o cubana, pero no abogó por la dictadura del proletariado, ni por ninguna dictadura de ninguna clase. De hecho, frente a la opinión extendida de que 
era un comunista irredento, siempre mantuvo una postura de recelo frente al dogmatismo comunista, como el mismo manifestó en referencia a su entrada en el PSUC, partido en el que militó y abandonó en diversas ocasiones a lo largo de su trayectoria: "Entré sin haberme deshecho de una profunda distancia psicológica respecto al comunismo, una gran distancia, muy fuerte. Es una situación ambigua que no ha desaparecido nunca. Y resulta especialmente curiosa ahora, cuando me llaman "el último intelectual comunista" (Tyras 28). ${ }^{4}$

\section{La resistencia a la dictadura}

Vázquez Montalbán nació a los dos meses de la victoria de Franco en un barrio de perdedores de la guerra civil, el Distrito V de Barcelona o El Raval, un barrio proletario degradado con todas las características de un gueto, más conocido tradicionalmente por su Barrio chino, y en el seno de una familia de trabajadores inmigrantes, de ideología anarquista en el caso de la madre, y comunista del PSUC en el del padre.

Los primeros meses de su vida estuvieron determinados por el exilio y posterior encarcelamiento de su padre por ser funcionario de la República. En el mismo año de su nacimiento, el fiscal del juicio militar franquista solicitó la pena de muerte para su padre por "traición e insurrección militar" (Saval, Una biografía 25), y el juez dictaminó veinte años de cárcel, de los que cumpliría cinco. La infancia y juventud de Vázquez Montalbán se desarrolla en unas circunstancias familiares de terrible marginación económica y represión política. El hecho de que a costa de grandes sacrificios por parte de sus padres, y gracias a unas grandes dotes personales para el estudio, el joven Vázquez Montalbán consiguiera completar los estudios de bachillerato en el barrio, constituía poco menos que un sueño para la mayoría de las familias de El Raval, condenadas al

\footnotetext{
4 Díaz Alonso mantiene la hipótesis de que la orientación ideológica de Vázquez Montalbán siempre estuvo más próxima del heterodoxo horizonte paramarxista del "Felipe", con su mezcla de humanismo, existencialismo, tercermundismo y critica al estalinismo, que de la cultura normativa y ortodoxa PCE-PSUC: "MVM fue hasta su muerte un marxista "felipista" (...). El eclecticismo adquirido por MVM en la primera parada de su vida política activa fue un equipaje que nunca abandonó y que se llevaría consigo al mucho más cerrado y disciplinado PCE-PSUC" (3).
} 
lumpen proletario. Pero que un muchacho de su extracción social pudiera traspasar las barreras infranqueables de las divisiones económicas y sociales de su época, y llegar a estudiar en la universidad, era poco menos que un milagro.

La entrada de Vázquez Montalbán en la Facultad de Filosofía y Letras de la Universidad de Barcelona en 1956 supone su entrada en otro universo sociocultural y conlleva su toma de contacto con la intelectualidad de la época, los grupos de resistencia al franquismo, y su paso a las actividades políticas, entrando a formar parte del clandestino grupo Nova Esquerra Universitaria (NEU), que luego se constituirá dentro del igualmente ilegal Frente de Liberación Popular (FLP) a nivel nacional, que en Cataluña se conocía como el FOC (Front Obrer de Catalunya). El FLP, conocido popularmente como el "Felipe", era una agrupación de nuevos diversos movimientos establecida en 1958 y situada en sus orígenes entre el marxismo y los sectores más avanzados del cristianismo, influenciada también por el humanismo y el existencialismo. La agrupación estaba formada sobre todo por estudiantes universitarios insatisfechos con la situación desestructurada de los partidos de izquierdas tradicionales, tales como el PSOE, el PCE, la CNT o el POUM, los principales partidos republicanos de izquierda, de ideología socialista, comunista, anarquista y trotskista respectivamente. El "Felipe" intentaba una renovación de los planteamientos fallados de las formaciones de izquierda histórica, optando por una estructura de frente, de coalición de fuerzas, más que de partido político, alejándose de la onda más prosoviética y estalinista, y situándose más cerca de las renovaciones acaecidas en los partidos democráticos de izquierda en Italia y Francia por esas mismas fechas.

La carrera política de Vázquez Montalbán comienza rápidamente y enseguida toma posiciones de liderazgo dentro de la organización clandestina. Como delegado del SEU y miembro de la ejecutiva del FOC, es detenido y fichado en Barcelona por las campañas de protesta y amnistía de 1959. Durante su obligatorio año de estudios en Madrid para finalizar la carrera se dedica a restablecer la célula del partido en la capital. Posteriormente abandona el "Felipe" e ingresa en el PSUC en 1961, el antiguo partido en el que había militado su padre durante la República. Fue una decisión pragmática, como señalaba Vázquez Montalbán, ya que era el único partido en la España de postguerra con posibilidades de oponer 
una resistencia efectiva a la dictadura: "Nos hicimos comunistas en este país (...) porque era el único partido que estaba en condiciones de luchar contra el franquismo al menos en los años 60" (Mercedes Milá, citado en Estrade199). El salto político resultaba lógico y coherente, tanto desde el punto de vista personal como colectivo, dada la afinidad ideológica entre el "Felipe" y el PSUC, que en palabras de Vázquez Montalbán tenían una "misma visión sobre la realidad y el mundo político" y porque tras la efectiva eliminación de otros grupos como los anarquistas, "la única instancia organizada era el Partido" (Tyras 27).

Este salto era también coherente una vez vencidos sus temores a la mayor represión policial, ya que el mayor reparo era el peor trato que recibían los militantes comunistas por parte de los cuerpos represivos del estado (Saval, Una biografía 62, 71). También se debía a que el PCEPSUC había ya comenzado por aquel entonces su proceso de desestalinización. Pero el peso sentimental de la militancia política familiar es a su vez un dato a tener en cuenta, en este caso una memoria histórica familiar (la antigua militancia de su padre en el PSUC). También es significativo el hecho de que su compañera de estudios y futura esposa, Anna Sallés, pertenecía a una familia que militaba en ese mismo partido. Así la causa personal se enmarca dentro de una causa histórica, familiar y colectiva más amplia.5

Durante ese tiempo, Vázquez Montalbán compaginaría sus estudios de Filosofía y Letras con la carrera en la Escuela de Periodismo de Barcelona. En esos años se implicó a fondo en las actividades políticas clandestinas, hasta el punto que más tarde reconocería que dedicó mucho más empeño a la lucha antifranquista que a los estudios en su etapa universitaria. Así lo indica su participación en las revueltas universitarias en solidaridad con la huelga de los mineros de Asturias en 1962, a raíz de la cual Vázquez Montalbán y Anna Sallés son detenidos y enviados a prisión. La experiencia de la cárcel, junto a los presos políticos Martí Capdevila, Salvador Clotas y Ferran Fullà, fue determinante en la educación política, intelectual y literaria de Vázquez Montalbán, ya que conformaron 18 meses de intensa educación mutua con estos compañeros, expertos en filosofía, literatura, y economía, e ideológicamente cercanos en

5 Sobre la evolución política del joven Vázquez Montalbán, véanse los trabajos biográficos de José Saval y Manuel Blanco Chivite, y el análisis de Diego Díaz Alonso. 
posturas anti-estalinistas. Durante su etapa carcelaria, Vázquez Montalbán escribe sus primeros poemarios y relatos, así como su primer libro de ensayo, Informe sobre la información, libro de teoría de la comunicación innovador que proporcionaba un análisis de óptica marxista, uno de los primeros libros de ciencias de la información publicado en España, que sería lectura obligada en la universidad durante muchos años.

A partir de esos años, las dificultades con la administración franquista, y en particular con la censura, fueron constantes, lo que dificultaba tanto la publicación de libros, como su actividad periodística, teniendo que dedicarse a trabajar como anónimo redactor de noticias y enciclopedias. Esto explicaría su posterior afición a escribir con múltiples seudónimos en revistas y periódicos. A pesar de ello, su actividad no escapaba la censura de los medios. Durante los últimos años del régimen franquista, Manuel Fraga, ex-Ministro de Información y Turismo, y responsable máximo del aparato censor del régimen, y posteriormente Ministro de Gobernación, resumía la condición de Vázquez Montalbán en unas pocas palabras comunicadas por teléfono a Manuel Ibañez Escofet, director de Tele/eXprés: "“Montalbán no puede firmar en este periódico. ¡Es un comunista!'. A lo que Ibáñez -inmenso- le respondió: 'Pero, Manolo... ¿cómo va a ser comunista un tipo que tiene un Simca 1000?"' (Bonet Mujica 38).

La situación de Vázquez Montalbán en el contexto político de la época sugiere una aparente contradicción. Por una parte, se debate entre la lucha contra la represión de la dictadura del franquismo, pero por otra también contra la autocomplacencia y la propia dinámica intolerante de cierta izquierda, y a veces del dogmatismo de su propia formación política.

En ese mismo sentido, Vázquez Montalbán iba también a contracorriente de la modernidad burguesa de la gauche divine que hacía estragos entre los sectores acomodados de la Barcelona de los sesenta. Esta era una nueva vanguardia cultural e intelectual de corte cosmopolita que aglutinaba corrientes de la cultura de resistencia catalanista, del marxismo y del pensamiento académico, a la que criticaba por ser un tanto "pija", pedante y autocomplaciente. Al mismo tiempo, su propia visión iconoclasta y desmitologizadora de la izquierda y su posición crítica con la anquilosada estructura del partido, así como su irónica lucidez y espíritu renovador, encontraron el rechazo de los sectores más tradicionales y 
ortodoxos. Así resultó incomprendido por una parte de la intelectualidad de izquierdas de la época debido a su labor de rescate de la cultura popular bajo el franquismo, y por su visión crítica de la propia intelectualidad y de la inefectividad de los programas políticos en la lucha contra el régimen.

Como marxista heterodoxo, Vázquez Montalbán fue frecuentemente visto con sospechas por los sectores dogmáticos del partido, por no encajar dentro de las directrices oficiales, y de las expectativas de lo que un intelectual de izquierdas significaba. La conciencia crítica de la "subnormalidad" del intelectual inmerso dentro del sistema, como ineficaz postura de resistencia frente al poder, era el eje en torno al que se articulaba su Manifiesto subnormal (1970), mezcla de manifiesto teórico revolucionario y programa vanguardista, en el que atacaba todos los dogmas y todas las seguridades, invitando a dudar de la propia duda. La obra sostenía una furibunda autocritica del intelectual, por la neutralización del espíritu revolucionario y los desencantos tras el reflujo de Mayo del 68, que Vázquez Montalbán siempre consideró poco más que un entretenimiento escenificado ("una opereta", en sus propias palabras) con pocas posibilidades de llegar a desestabilizar el sistema y mucho menos de transformar la realidad. Su visión irónica y crítica de la realidad incluía la propia mitología revolucionaria post-sesentaiochista, como se desprende de esta reflexión posterior:

Cuando publiqué Manifiesto subnormal una parte de la izquierda más ortodoxa me acusó de estar al margen de las pautas culturales y políticas del socialismo científico y de la razón estratégica de los partidos marxistaleninistas. Recuerdo condenas duras en órganos de la prensa clandestina universitaria del PCE, a pesar de que yo era militante de un partido tan afín como el PSUC. También los marxistas más marxistas que los jóvenes universitarios del PCE me descalificaron hasta el punto de descubrir ramalazos fascistas en mi manifiesto. ("De la subnormalidad al planeta de los simios" 17)

Esta misma visión cáustica e irreverente se reproducirá en toda su literatura denominada "subnormal", producida entre 1968 y 1974, que sería posteriormente recogida en sus Escritos subnormales. Este posicionamiento auto-crítico "subnormal", sin embargo, mantiene una continuidad con muchos de los radicales plantea- 
mientos éticos y estéticos que reaparecerán décadas más tarde, como algunas de las penúltimas obras de la serie Carvalho, Sabotaje Olímpico o Roldán, ni vivo ni muerto, así como otras obras contemporáneas como El estrangulador y Panfleto. Esta evolución es consecuencia del propio devenir de los acontecimientos políticos y la progresiva crisis de la izquierda en el mundo occidental. ${ }^{6}$

\section{Crónica de la Transición}

Tras la restauración de la democracia, el PSUC va a entrar en un periodo de crisis interna, entre los sectores leninistas y los renovadores, los prosoviéticos y los eurocomunistas. El partido sufre una crisis de identidad y va perdiendo fuerza elección tras elección, agotando el capital simbólico acumulado durante los años de la resistencia antifranquista. Vázquez Montalbán es elegido miembro del comité ejecutivo del PSUC, como figura conciliadora, ya que gozaba del respeto de ambas facciones, quizás porque como parte del "sector renovador" no se casaba con ninguna. ${ }^{7}$

En el ámbito de la comunicación Vázquez Montalbán se entrega a una gran variedad de empeños periodísticos y literarios. Su fuerte compromiso ético y su conciencia de la responsabilidad social del escritor de recordar el pasado, de hacer la crónica del presente, de dar voz a los sin voz y desenmascarar los mecanismos del poder, dependía de su capacidad básica de lograr la comunicación con un amplio público lector. Vázquez Montalbán se basó en los planteamientos del teórico marxista italiano Antonio Gramsci, que conocía desde su etapa carcelaria, para utilizar la cultura popular como un instrumento de rebelión contra las fuerzas hegemónicas dominantes de la sociedad, convirtiendo el medio en un instrumento contra sí mismo. En ese sentido abogaba por la reutilización y resignificación de los lenguajes populares como una manera de intervención política y de crear medios expresivos populares que pudieran canalizar resistencias al poder. Esta práctica contra-hegemónica ten-

6 Véase al respecto mi estudio Crónica general del desencanto: Vázquez Montalbán Historia y ficción.

7 Su crítica al estalinismo y al programa de "imperialismo soviético" ya había aparecido en ¿Qué es el imperialismo? (50-54), publicado inmediatamente después de la muerte de Franco. 
dría el efecto añadido de desmarginalizar los géneros populares, ya fueran la revista, la canción, el cine o la novela popular, tradicionalmente considerados inferiores y subliterarios.

La saga detectivesca de Pepe Carvalho, ideada como una crónica de la Transición, ilustra de manera ejemplar esta tendencia. El personaje central aporta una mirada extravagante que le permite al autor despotricar contra todo, sin las ataduras de un guión político establecido. La arbitrariedad del personaje, que ha sido tanto militante del PCE como agente de la CIA en diferentes etapas de su vida, y cuyas iniciales coinciden irónicamente con las del Partido Comunista, le sirve como instrumento de observación al autor, a través del cual puede focalizar una visión crítica de la sociedad en proceso de transformación tras el final de la dictadura. El personaje de Carvalho, a través de su ambigüedad y relatividad, y su misma esquizofrenia ideológica, es un vehículo idóneo para una visión dialéctica de la realidad social. Saval ha analizado en su artículo titulado "La lucha de clases se sienta a la mesa" la visión marxista de la realidad social que presentan las novelas de la saga Carvalho. En ellas queda reflejada la violencia de las relaciones de poder económicopolítico y la opresión de los sectores bajos por parte de las clases dominantes, algo que efectivamente se comprueba en todas las novelas de la serie, convirtiéndose de hecho en el tema principal de algunas de las más destacadas, como La soledad del manager o Los mares del Sur.

Pero quizás la obra que mejor refleja en clave ficcional la compleja relación de Vázquez Montalbán con el Partido Comunista sea su novela Asesinato en el Comité Central, publicada en 1981, que escudriña la descomposición interna del PCE. En esta claustrofóbica pero catártica novela que exorcizaba los demonios del pasado se mostraban las disensiones internas dentro del partido y los movimientos de oposición contra el dogmatismo ortodoxo. Como una especie de novela-enigma del tipo "misterio de habitación cerrada" pero en clave política, Pepe Carvalho se desplaza a Madrid para investigar el asesinato del secretario general del partido, cometido durante un apagón en medio de una reunión del Comité Central. El canibalismo político, el declive del eurocomunismo y el sentimiento generalizado de confusión y desilusión de aquellos años resuenan en toda la novela, así como los ecos de la agitación política que dio origen al intento de golpe de Estado del 23-F en el hemiciclo de las Cortes españolas ese mismo año. En esta densa novela, el autor salda sus 
cuentas con el Partido desde dentro, puesto que él mismo había sido un militante crítico y revisionista del PSUC así como miembro de su Comité Central en diferentes etapas de su vida. En una conversación con Blanco Chivite, el autor confesaba con franqueza las enormes dificultades de escribir esta novela y el gran pudor ideológico de hacerlo: "Era muy difícil escribir una novela sobre el PCE, desde dentro del PCE, sin ser disidente, sin hacerlo como el clásico disidente que se ha marchado, y al mismo tiempo tratando de explicar qué coño está pasando y qué coño va a pasar, porque la novela está publicada antes de la gran liquidación, antes de la merienda de rojos" (69).

Los planteamientos básicos de Vázquez Montalbán basados en la teoría marxista continúan siendo los mismos, si bien muy alejados de cualquier ortodoxia dogmática. En una entrevista mantenida con el autor en 1987, republicada recientemente en 2013, Vázquez Montalbán explicaba con lucidez su postura sobre el materialismo histórico del marxismo clásico como forma dialéctica de conocimiento. El autor entiende este no como dogma ideológico inamovible, que conformaría una retórica trasnochada o una religión inútil, sino como una forma de diagnóstico de una realidad política y socioeconómica determinada, que sigue teniendo validez como acercamiento, aunque las circunstancias hayan cambiado, y a pesar de que los intentos de poner la teoría en práctica hayan sido malogrados. Significa una comprensión de la Historia y del presente histórico, pero desde unas realidades y unos códigos de lenguaje actuales, que no son los mismos del siglo XIX ni los de la revolución soviética. Vale la pena reproducir la respuesta del autor a pesar de su extensión:

...yo creo que si el materialismo histórico tiene en estos momentos alguna influencia real y alguna posibilidad de servir para algo es precisamente en lo que menos pueda tener de dogma y en lo que más pueda tener de un diagnóstico ya comprobable, empírico. El materialismo histórico - ya nos metemos en el terreno de lo dialéctico - en un momento determinado da explicación a lo que es evidente, un desorden determinado causado por unos elementos determinados, y diagnostica el sentido histórico, es decir, el viaje histórico que ha llevado a ese desorden, y explica por qué se ha producido. Yo creo que aún estamos moviéndonos dentro de ese marco, lo que ocurre es que no estamos moviéndonos como en el momento del diagnóstico. En aquel momento el diagnóstico puede ser confundido con un dogma. Después de eso han pasado 140 años y todos los términos que se mueven dentro de él se han resituado: el capitalismo ya no es el mismo, ya se ha vacunado, muchos 
de los hijos de los capitalistas han sido marxistas en una época de su vida, luego han vuelto a la casa del padre y le han prestado el lenguaje. Eso ha producido cambios tremendos. El hecho de que lo que era una teoría fuera convertido en práctica en un lugar determinado del mundo y en cierto sentido haya inutilizado el modelo, eso también ha repercutido enormemente. El materialismo histórico es una descripción determinada de la evolución de la Historia que genera unas contradicciones determinadas dentro de las cuales aún nos encontramos. Pero evidentemente lo que sería un error ahora es tratar de aprehenderlas con mecanismos lingüísticos, veracidades y comprobaciones del XIX. Es ahí donde sería un discurso totalmente retórico, una obra retórica que no serviría absolutamente para nada, o abundar en lo que ha sido durante una época una religión, unas verdades reveladas. (El ruido y la furia 67)

\section{El final del milenio y el final de la Historia}

La caída del muro de Berlín y la disolución del bloque soviético va a confirmar la entrada en una nueva era de post-Guerra Fría, de imposición de un nuevo orden universal y la victoria del neoliberalismo economicista como una gran verdad de implantación prácticamente global. Para muchos, hablar de marxismo o comunismo en este nuevo contexto se vuelve casi un absurdo cuando no un anacronismo. Sin embargo, la posición ideológica de Vázquez Montalbán sigue siendo la misma, aunque en las nuevas coordenadas políticas e históricas ahora se trata de desenmascarar a un nuevo y peligroso contrincante ideológico, que pudiéramos identificar con un cierto pensamiento postmoderno predicador del final de las grandes narrativas, pero que constituye en sí mismo una gran narrativa totalizante de la que es muy difícil escapar.

Y es que en realidad, como manifestaba en una conversación en 1992, este pensamiento representa un nuevo agente del sistema al servirle de coartada, una avanzadilla del nuevo orden global, instalado en la conformidad, el ahistoricismo, y la dictadura de los mercados:

Ahora aparece todo un frente aparentemente muy audaz de una nueva vanguardia intelectual que predica precisamente la no ingerencia, el no mesianismo, pero en realidad su ingerencia y mesianismo es presentar un proyecto de sociedad único e inapelable, casi con unos mismos acentos totalitarios que pudiera haber adoptado un mensaje marxista y utópico en esa dirección hace cuarenta o cincuenta años. (El ruido y la furia 74) 
Vázquez Montalbán reaccionaba aquí a los acontecimientos políticos que estaban inaugurando la nueva etapa histórica de la globalización neoliberal y a los agoreros del pronosticado final de la historia (Fukuyama). Además mostraba su desconfianza ante la campaña de las rebajas ideológicas de la postmodernidad ahistoricista. La implantación de la globalización como nueva ideología dominante requeriría un nuevo esfuerzo de reposicionamiento por parte de una izquierda que no debería anquilosarse en estrategias y dogmas del pasado:

La única posibilidad que la conciencia comunista fuera el final y el comienzo de una nueva conciencia capaz de enfrentarse al nuevo desorden creado por la revolución tecnológica, radicaría en su inteligencia y su capacidad por ser más una fuera sugestiva de una nueva izquierda que en una fuerza simplemente superviviente y administradora de lo que queda de inversiones y ahorros históricos. (L'esquerra necessària)

Vázquez Montalbán se sitúa nuevamente en la vanguardia internacional de los movimientos de resistencia a los poderes hegemónicos y de rechazo del neoliberalismo, así como en la búsqueda de nuevas alternativas, en cualquier parte del mundo, abanderando los movimientos antiglobalización, las reivindicaciones anticoloniales e indigenistas, y los movimientos en defensa de la memoria histórica en España y Latinoamérica. Ramoneda resume esta esplendorosa e infatigable etapa final de "comunista irredento":

Manolo Vázquez Montalbán formaba parte de la media docena de intelectuales europeos -comunistas irredentos, podría decirse- que acudían a la llamada de cualquier signo de emergencia de algún movimiento radical que, en algún lugar del mundo, apareciera como portador de una nueva esperanza. La causa zapatista, el pacifismo antiamericano y los movimientos antiglobalización habían sido sus últimas apuestas. ("Déjame que sea el que apague") ${ }^{8}$

\footnotetext{
8 El propio autor reconocía esta situación, no sin cierta ironía autocrítica, al ser plenamente consciente de la contradicción de ser un burgués europeo de izquierdas, que trata de encontrar otras revoluciones posibles fuera de su entorno inmediato: "Me reconozco sensible ante el argumento de que los burgueses ilustrados de izquierda nos solazamos con las revoluciones lejanas, esas incómodas revoluciones que no quisiéramos interpretar como protagonistas".
} 
En el contexto de las rebajas ideológicas del neoliberalismo globalizador, Vázquez Montalbán reflexiona sobre la erosión de ciertos conceptos marxistas clásicos y de la propia supervivencia de términos como socialismo y comunismo, que han sido usurpados, adulterados y demonizados, y que quedan a la espera de una reivindicación de sus contenidos originales. En el prólogo expresamente escrito para la edición italiana de Moscú de la Revolución en 1995 afirma lo siguiente:

Pero las palabras tienen dueño, como asegura Lewis Carroll en Alicia en el país de las maravillas y de palabras como socialismo o comunismo se habían apoderado el estalinismo y el breznevismo hasta hacerlas inservibles durante décadas, hasta que se apoderen de ellas otra vez una izquierda tan inocente como la que inició la marcha reivindicativa a partir de la Revolución Industrial. (Prólogo) ${ }^{9}$

En la postdata a la última edición de Escritos subnormales, titulada "De la subnormalidad al planeta de los simios", fechada igualmente en 1995, Vázquez Montalbán se ve a sí mismo identificado como un "recalcitrante poscomunista", o comunista después del comunismo, por parte de la "secta neoliberal" (17-18). El autor defiende con coherencia y tenacidad la integridad de sus principios, y desenmascara los intereses creados de aquellos empeñados en borrar la incómoda historia de los movimientos de justicia social, y de todo aquello que significa cambiar la historia en un sentido emancipador: "La intolerancia neoliberal trata de descalificar todo lo que niega la instalación en el presente como fatalidad, todo lo que propone utilizar la memoria histórica crítica y el derecho a la esperanza no teologal que implica cambiar la materia y el espíritu de las relaciones humanas" ("De la subnormalidad al planeta de los simios" 18). Se resiste a abandonarse a la imperante ideología del neoliberalismo y la dictadura de los mercados, y arremete contra las élites políticas, económicas y culturales de las clases dirigentes que "practican el reduccionismo falsamente identificador de acusar a todos los críticos del sistema de 'nostálgicos de la monstruosa alternativa del socialismo $-$

9 Otra reflexión parecida apareció en la revista Ajoblanco, en una conversación con Eduardo Haro Tecglen: "Pero aquí funciona una maldición que no es marxista, sino de Lewis Carroll: las palabras tienen dueño. De la palabra comunismo se ha apoderado el Estalinismo. ¿Quién sale ahora con esa palabra a la calle?” (“Conversación”). 
real derrumbado con el muro de Berlín’” (18). Vázquez Montalbán sigue firme en sus convicciones de que la teoría marxista es el modo ideal de conocimiento de la realidad capitalista, se disfrace esta como se disfrace:

"El marxismo sigue sobreviviendo como un sistema de análisis, como un método de comprensión de la historia, no en balde es el mejor diagnóstico que hasta ahora se ha hecho del capitalismo, y es capitalismo todo lo que toamos y respiramos" (Panfleto 65). ${ }^{10}$

Nuevamente tenemos una muestra de la coherencia y fidelidad del pensamiento de Vázquez Montalbán a sus principios, que en 1995, tras el desbarajuste del "socialismo real" por un lado, y por el otro, la apoteosis del final de la historia y la victoria del neoliberalismo como única ideología planetaria, todavía reivindicaba los mismos principios emancipatorios que defendía en 1968. Así veía el autor una lógica de continuidad entre los planteamientos críticos que suscribía en los años 60, que le llevaron a escribir Manifiesto subnormal (1970), producto del reflujo de mayo del 68, y Panfleto desde el planeta de los simios (1995), resultado de la implantación del nuevo orden universal llamado globalización. Y tan crítico se muestra de la ligereza y fragilidad de los movimientos contestatarios del 68, de la represión de la primavera de Praga por los tanques soviéticos, fracasos históricos de la izquierda, así como del no menor fracaso histórico del capitalismo en su incapacidad para conseguir un mundo más justo y más feliz, provocando una irracional carrera hacia el desastre. Ante este panorama, Vázquez Montalbán reivindica la racionalidad crítica frente a la irracionalidad del sistema, y la emancipación frente a la servidumbre:

Afortunadamente puedo releerme. Y no solo Escritos subnormales, sino una larga ristra de intervenciones que demuestran el parentesco de mis posiciones críticas de 1968 con las de ahora, beneficiado actualmente por la caída de las esperanzas de cartón piedra y por la progresiva evidenciación de que si bien fracasó incluso la intentona de un socialismo con rostro humano machacada por los socialistas 'realmente existentes', no por eso el capitalismo ha conseguido universalizar la riqueza como instrumento material de la felicidad en este mundo y sigue siendo empeño necesario la lucha para conse-

10 Véanse los trabajos de Izquierdo (2001) y Balibrea (2002) sobre la respuesta ideológica y estética del autor frente a los desafíos de la globalización. 
guir no ya mejorar las condiciones de vida de los vencidos por el mercado, la inmensa mayoría a escala planetaria, sino incluso garantizar la supervivencia de la humanidad amenizada por la irracionalidad de un crecimiento sin cerebro ecológico. (18)

Para Vázquez Montalbán, la dinámica de la Guerra Fría ha sido sustituida por otra nueva constelación, pero la ordenación del mundo en el planeta de los simios globalizados sigue la misma dinámica de verdugos y víctimas, explotadores y explotados. Su Panfleto es por ello un intento de comprensión de una desconcertante realidad alucinada que adquiere el aspecto de una pesadilla surreal. De hecho, la mayor parte de los fundamentales escritos de Vázquez Montalbán en estos últimos años, sus ensayos, novelas y columnas periodísticas, así como sus intervenciones públicas, se vuelcan sobre esta temática: la mecánica del poder, la globalización y la antiglobalización, la reivindicación de la memoria histórica, la lenta agonía del comunismo y la búsqueda de esperanzas y alternativas, y de nuevos motores y sujetos históricos capaces de cambiar la historia. La reivindicación de la memoria histórica es explícita y central en su Autobiografia del general Franco así como en Quinteto de Buenos Aires o Galíndez, donde también se refleja la lucha del comunismo y el anticomunismo en el contexto internacional de la guerra fría y sus consecuencias en el panorama contemporáneo. En Pasionaria el autor rehúye del retrato hagiográfico, realizando una autocrítica a la historia del partido comunista y el estalinismo, como forma de catarsis necesaria. En Moscú de la revolución, que confiesa es una "parte de la arqueología de mi sentimentalidad" (11), reitera su crítica anti-estalinista pero también su defensa de los principios revolucionarios. $Y$ dios entró en La Habana, a pesar de su visión relativizadora, preocupado por la lucha de los derechos humanos y las libertades democráticas, sigue apostando por la posibilidad de la revolución, del diálogo, en su determinación de que la historia no ha terminado. Marcos: El señor de los espejos y Eric y Enide, retratan el surgimiento de las luchas indígenas en el contexto de la represión de los grupos minoritarios protagonizada por las fuerzas de la globalización. $O$ César o nada presenta una metafórica reflexión sobre los mecanismos del poder y la crisis del estado nación en el contexto de la globalización. El estrangulador ofrece una carga de pura dinamita verbal contra el cacareado final de la historia. Milenio, por último, es un viaje final alrededor del mundo y que aporta una mirada crítica a los efectos 
Memoria, ideología y heterodoxia: Contra el pensamiento hegem ... 21

devastadores del neocolonialismo y la globalización en los cinco continentes.

El conjunto de los ensayos, novelas y otros escritos de Vázquez Montalbán en estos años indagan sobre la construcción del poder y de las posibilidades de resistencia. Tratan de explorar alternativas a la implacable dictadura de los mercados, denunciar las corrientes neocoloniales de la globalización y luchar contra la proclamación del final de la Historia, con la constatación de la victoria del economicismo neoliberal como nuevo dogma y doxa universal. En Panfleto, el autor se explayaría sobre la necesidad de seguir buscando respuestas, ya que el diagnóstico sigue haciendo preguntas: "No hay verdades únicas, ni luchas finales, pero aún es posible orientarnos mediante las verdades posibles contra las no verdades evidentes y luchar contra ellas" (Panfleto 145). Instalados en el planeta de los simios que han borrado su pasado, Vázquez Montalbán nos recuerda que el compromiso de cambiar la Historia y cambiar la vida es un recuerdo por el que todavía vale la pena luchar.

La posición ideológica de Vázquez Montalbán se ha caracterizado siempre por una lucha contra las no verdades, contra el pensamiento hegemónico y contra la ortodoxia en cualquiera de sus formas, y a favor de un compromiso con la realidad social, con la memoria, y la búsqueda de alternativas posibles de cambio. Como hemos visto, su trayectoria vital así como su obra literaria y ensayística constituyen la crónica de una heterodoxia. En los nuevos tiempos del neoliberalismo planetario en que las no verdades se disfrazan de dogmas inevitables y las noticias falsas invaden y se instalan como nuevas doxas, se renueva la necesidad de denunciar, resistir, desde el pensamiento crítico y heterodoxo como reiteradamente hizo Vázquez Montalbán.

\section{Bibliografía}

Balibrea, Mari Paz. En la tierra baldía. Manuel Vázquez Montalbán y la izquierda española en la postmodernidad. Barcelona: El viejo topo, 1999. Impreso.

---. "Escrituras de la globalización: espacio y tiempo en la obra reciente de Manuel Vázquez Montalbán". Violence politique et ecriture de la elucidation dans le bassin méditerranéen. Eds. Georges Tyras y Claude Ambroise. Grenoble: Presses de la Université Stendhal, 2002. 207-220. Impreso. 
Blanco Chivite, Manuel. Manuel Vázquez Montalbán \& Pepe Carvalho. Colección ¿YO SOY ASÍ? Madrid: Grupo Libro 88, 1992. Impreso.

Bonet Mujica, Lluís. "Periodismo en tiempos de plomo" La Vanguardia 21 Octubre, 2003: 38. Impreso.

Colmeiro, José. El ruido y la furia: Conversaciones con Manuel Vázquez Montalbán, desde el planeta de los simios. Madrid: Editorial Iberoamericana, 2013. Impreso.

---. Crónica general del desencanto: Vázquez Montalbán - Historia y ficción. Barcelona: Anthropos, 2014. Impreso.

---. Introducción. El Pianista de Manuel Vázquez Montalbán. Madrid: Cátedra, 1917. 9-97. Impreso.

"Conversación con Haro Tecglen y Vázquez Montalbán. Coordinada por Óscar Fontrodona y José Ribas" Ajoblanco (enero 1993). Obtenido el 15 de mayo de 2017. Sitio web: http:// www.vespito.net

Díaz Alonso, Diego. "Los límites del comunismo. Manuel Vázquez Montalbán y la crisis de la izquierda". Primer Congrés d'Història del PSUC. 2006. Obtenido el 15 de mayo de 2017. Sitio web: http://fcim.cat/historiapsuc/pdfs/diego\%20diaz\%20alonso.pdf

Estrade, Florece. Manuel Vázquez Montalbán. Barcelona: Ediciones de la Tempestad, 2004.

Gil de Biedma, Jaime. Obras. Poesía y Prosas. Edición de Nicanor Vélez. Madrid: Galaxia Gutenberg, 2010. Impreso.

Gramsci, Antonio. Selections from Cultural Writings. Trad. William Boelhower. Eds. David Forgacs y Geoffrey Nowell-Smith. Cambridge: Harvard UP, 1985. Impreso.

Izquierdo, José María. "Escribas sentados en planetas de simios: Ideas políticas en la obra de Manuel Vázquez Montalbán" Pensadores y escritores hispánicos. Eds. Inger Enkvist y Eduardo Naranjo. Lund: Heterogénesis, 2001.103-124. http://www.enmitg.com/izquierdo/literatura/mvm/index.html. Web

---. "Construcción de conciencia crítica e hibridación. Dos constantes en la obra de Manuel Vázquez Montalbán” MVM: Cuadernos de Estudios Manuel Vázquez Montalbán, 1.1 (2013): 3-18. Web.

Luzán, Julia. "Encarna soy yo". La Calle, 23 Octubre, 1979. Obtenido el 15 de mayo de 2017. Sitio web: http://www.vespito.net

Ramoneda, Josep. "Déjame que apague la luz". El País 23 Octubre 2003. Web. 15 may 2017. 
Memoria, ideología y heterodoxia: Contra el pensamiento hegem... 23

Salgado, Francesc. "Prólogo, La vida no es como la esperábamos". Manuel Vázquez Montalbán. Obra periodística. Vol. 3. Las batallas perdidas. 1987-2003. ed. Barcelona: Debate, 2012. Impreso.

Saval, José Vicente. "La lucha de clases se sienta a la mesa en Los mares del sur de Manuel Vázquez Montalbán." Revista Hispánica Moderna 48 (1995): 389-400. Impreso.

---. Vázquez Montalbán. Una biografía revisada. Barcelona: Alrevés, 2013. Impreso.

Tyras, Georges. Geometrías de la memoria. Conversaciones con Manuel Vázquez Montalbán. Granada: Zoela Ediciones, 2003. Impreso.

Vázquez Montalbán, Manuel. Informe sobre la información. Barcelona: Fontanella, 1963. Impreso.

---. Manifiesto Subnormal. Barcelona: Kairós, 1970. Reeditado en Escritos subnormales. Barcelona: Seix Barral, 1989. Impreso.

--- ¿Qué es el imperialismo? Barcelona: La Gaya Ciencia, 1976. Impreso.

---. La soledad del manager. Barcelona: Planeta, 1977. Impreso.

---. "Encarna soy yo", La Calle 23 octubre, 1979. Impreso.

---. Los mares del sur. Barcelona: Planeta, 1979. Impreso.

---. Asesinato en el comité central. Barcelona: Planeta, 1981. Impreso.

---. Praga. Barcelona: Lumen, 1982. Impreso.

--- El pianista. 1985. Ed. José Colmeiro. Madrid: Cátedra, 2017. Impreso.

---. Rafael Ribó: el optimismo de la razón. Barcelona: Planeta, 1988. Impreso.

---. L'esquerra necessària. Barcelona: Fundació Caixa de Barcelona, 1989. Impreso.

---. Galíndez. Barcelona: Planeta, 1990. Impreso.

---. Moscú de la Revolución. Barcelona: Planeta, 1990. Impreso.

---. Autobiografía del general Franco. Barcelona: Planeta, 1992. Impreso.

---. Sabotaje olímpico. Barcelona: Planeta, 1993. Impreso.

---. Roldán, ni vivo ni muerto. Barcelona: Planeta, 1994. Impreso.

---. El estrangulador. Barcelona: Mondadori, 1994. Impreso.

---. Panfleto desde el planeta de los simios. Barcelona: Crítica, 1995. Impreso.

---. Pasionaria y los siete enanitos. Barcelona: Planeta, 1995. Impreso. 
---. Quinteto de Buenos Aires. Barcelona: Planeta, 1997. Impreso.

---. O César o nada. Barcelona: Planeta, 1998. Impreso.

---. Y Dios entró en La Habana. Madrid: El País/Aguilar, 1998. Impreso.

---. Marcos: El señor de los espejos. Madrid: Aguilar, 1999. Impreso.

---. "De la subnormalidad al planeta de los simios" Escritos subnormales. Barcelona: Mondadori, 2000: 17-19. Impreso.

---. Erec y Enide. Barcelona: Planeta, 2002. Impreso.

---. Milenio Carvalho. 2 volúmenes (1: Rumbo a Kabul; 2: En las antípodas). Barcelona: Planeta, 2004. Impreso.

---. Prólogo original para la traducción italiana de Moscú de la Revolución. (La Mosca della rivoluzione. Milán: Feltrinelli, 1995) Inédito. Obtenido el 15 de mayo de 2017. Sitio web: http://www.vespito.net 